\title{
FPGA-based Centralized Controller for Multiple PV Generators Tied to the DC Bus
}

\author{
Ashraf Ahmed*, Pradeep Ganeshkumar ${ }^{*}$ Joung-Hu Park ${ }^{\dagger}$, and Hojin Lee ${ }^{* *}$ \\ ${ }^{*}$ Department of Electrical Engineering, Soongsil University, Seoul, Korea \\ ${ }^{* *}$ School of Electronic Engineering, Soongsil University, Seoul Korea
}

\begin{abstract}
The integration of photovoltaic (PV) energy sources into DC grid has gained considerable attention because of its enhanced conversion efficiency with reduced number of power conversion stages. During the integration process, a local control unit is normally included with every power conversion stage of the PV source to accomplish the process of maximum power point tracking. A centralized monitoring and supervisory control unit is required for monitoring, power management, and protection of the entire system. Therefore, we propose a field-programmable gate array (FPGA) based centralized control unit that integrates all local controllers with the centralized monitoring unit. The main focus of this study is on the process of integrating many local control units into a single central unit. In this paper, we present design and optimization procedures for the hardware implementation of FPGA architecture. Furthermore, we propose a transient analysis and control design methodology with consideration of the nonlinear characteristics of the PV source. Hardware experiment results verify the efficiency of the central control unit and controller design.
\end{abstract}

Key words: Centralized controller, DC grid, FPGA, Parallel operation

\section{INTRODUCTION}

The rapid increase in the demand for clean energy sources has given rise to the idea of connecting PV generation sources to utility grids [1]. Worldwide PV installation exceeded $100 \mathrm{GW}$ in 2012 and has a potential to increase 2.5fold within the next five years [2]. Therefore, PV will become a major electricity source in the near future. Considerable attention has recently been directed toward the integration of PV generators with the DC grid and intermeshing such generators with the AC network, especially at low- and medium-voltage levels [3]-[5]. Integrating PV systems with the DC grid will reduce the number of power conversion stages and thus increase overall conversion efficiency. The efficiency of integrated DC loads, such as electric vehicle batteries, to the grid will also be improved [6], [7]. Different

Manuscript received Jan. 15, 2014; accepted Apr. 30, 2014

Recommended for publication by Associate Editor Yujin Song.

${ }^{\dagger}$ Corresponding Author: wait4u@ssu.ac.kr

Tel: +82-2-828-7269, Fax: +82-2-817-7961, Soongsil University

*Dept. of Electrical Engineering, Soongsil University, Korea

${ }^{* *}$ School of Electrical Engineering, Soongsil University, Korea methods can be used to integrate PV sources with the DC grid. Parallel connection of PV generators is a widely used method. A DC/DC converter is used to integrate each PV generator to the $\mathrm{DC}$ grid.

One technological challenge arising from the integration of PV systems with multigenerator systems is overall system control. A two-layered control architecture (hierarchies) is typically required for the parallel-connected power interfaces of sources. The first layer is the local control unit, which should be included in every DC/DC converter for maximum power point tracking (MPPT) and fault protection. The second layer is the central monitoring and supervisory unit embedded in the system to monitor the fault and/or power flow of parallel-connected PV systems. Having a central monitoring unit is essential for this system, especially for typical stand-alone mode operation [8], [9]. This unit should be capable of communicating and supervising the local control units through cutting-edge communication technologies [7].

A simplified schematic diagram of the conventional control architecture is shown in Fig. 1. Several DC/DC converters, such as DC/DC conv. (1) and DC/DC conv. (n), 
are connected in parallel. These converters interface between PV generators [PV G (1) to PV G (n)] with the DC bus. Every DC/DC converter in the architecture has its own local control unit [LCU (1) to LCU (n)]. The control architecture in Fig. 1 needs a local controller for each PV subsystem. Consequently, system control coordination among the modules and the cost competitiveness of the entire system worsen. Integrating local control units with the central monitoring unit will significantly reduce manufacturing cost for controller implementation because of easy coordination. Several instantaneous control tasks under stand-alone operations and islanding detection will become easier to apply. Furthermore, system installation will become easier and cheaper. System control is easily configured and updated during the system lifetime. Additionally, efficient data exchange is achieved between every local control unit and the central monitoring unit. This exchange enables the supervisory controller unit to coordinate the operation of every local controller efficiently. Therefore, integrating multiple control units into a single centralized unit provides several logical and physical proficiencies. A schematic diagram of the proposed centralized control and monitoring unit is shown in Fig. 2. A serious technical challenge is finding a suitable hardware device to process multiple control loops instantaneously.

In addition to analog controllers, digital signal processors (DSPs) and field-programmable gate arrays (FPGAs) are the main technological solutions for controller implementation. DSP-based controllers are more suitable for the application that process large data and complex mathematical calculations. Whereas, FPGA-based controllers are appropriate for algorithms that require parallel operation [10]. With the capability of parallel operation and fast performance, several local controllers can be integrated into a single FPGA device with equivalent or better control performance. DSP-based devices are expensive because DSPs are founded on sequential processing units. Therefore, we used an FPGA-based central control unit in this study.

This study focuses on integrating many local control units into a single central unit. The FPGA-based central control unit, including the algorithm description and FPGA design, is proposed in Section II. System modeling, transient analysis, and local controller design methodology are presented in Section III. The proposed control architecture is verified on the basis of the experimental test results in Section IV.

\section{FPGA-BASED CENTRAL CONTROLLER}

FPGAs consist of a matrix of configurable logic blocks (CLBs). CLBs are connected to one another through a reprogrammable network. The code downloaded to the

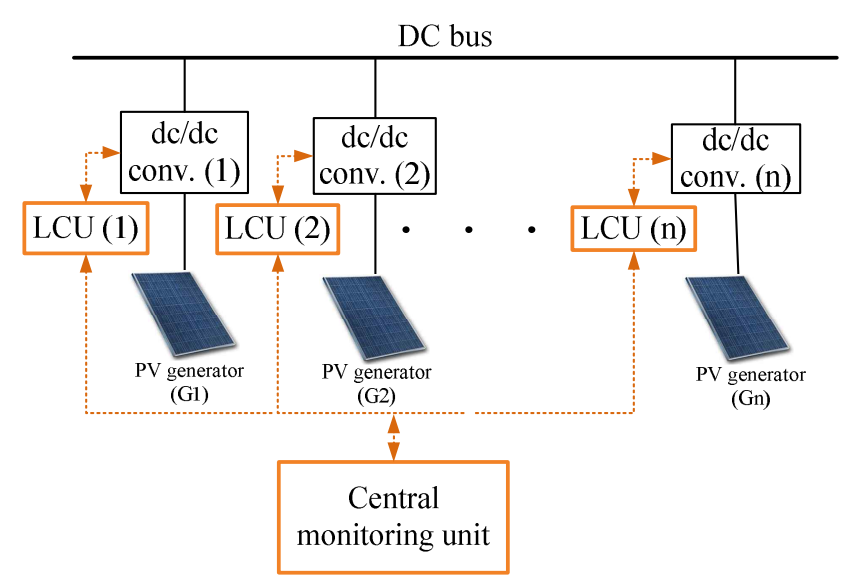

Fig. 1. Conventional control configuration of distributed PV power systems with local controllers.

DC bus

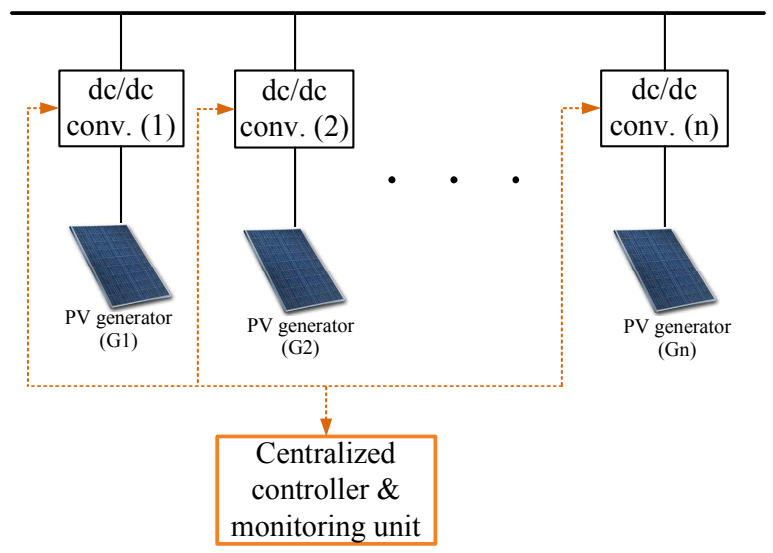

Fig. 2. Proposed central architecture of the distributed PV power system.

memory cells configures both the CLBs and the network connection. The memory cells (e.g., Flash, EPROM, or SRAM) enable the FPGA to be as reprogrammable as microprocessors [11]-[13]. FPGAs consist of CLBs; each CLB unit contains a number of logic units called slices. A slice contains a number of look-up tables (LUTs) and registers. The design objective of FPGA-based controllers is to develop an optimized hardware architecture for the given algorithm. This architecture should satisfy the minimum number of slices, LUTs, and registers without violating the hardware processing time response. RAM blocks can also be used if necessary. In the first stage of the design process, the central control unit algorithm is divided into two units (modules): the MPPT algorithm and the PI controller. A data flow graph (DFG) is then used to design and optimize all units individually.

The proposed central control unit controls multiple PV systems. Each PV system contains a solar array and DC/DC boost converter, as shown in Fig. 2. The primary task of the proposed central controller is to perform MPPT control for 
the individual PV subsystems tied to the common DC grid. The FPGA-based central control unit senses and utilizes the voltage and current information of each PV subsystem to perform MPPT control. The main control task of the central control and monitoring unit is to perform MPPT for every paralleled PV system. Some individual methods, such as open- circuit voltage control and short-circuit current control, as well as hill climbing, pilot cells, and artificial intelligence techniques, are applied to achieve MPPT control in PV power generation systems [14]-[19]. Hill climbing is generally used in PV applications. This approach is mainly divided into perturb and observe (P\&O) and incremental conductance (IC) algorithms [20]-[23]. The simple structure, ease of implementation, and reduced calculations make the $\mathrm{P} \& \mathrm{O}$ algorithm suitable for FPGA implementation. The perturbation variable determines whether the $\mathrm{P} \& \mathrm{O}$ method is a direct or indirect control algorithm. The duty cycle for the direct controller is generally used as the perturbation variable. This method is the simplest approach to achieve MPPT. However, one vital drawback of this method is the loss of MPPT control during load voltage fluctuations. Furthermore, the uncontrolled step response in the duty cycle produces oscillations in PV output power. These oscillations misguide the controller and cause it to perturb the power away from the maximum power point, which results in low MPPT efficiency. These drawbacks can be overcome by using the feedback controller. Whereas, in the indirect control method, PV voltage or current feedback is used to track the maximum power point reference determined by the $\mathrm{P} \& \mathrm{O}$ algorithm. Therefore, the $\mathrm{P} \& \mathrm{O}$ algorithm with feedback voltage control loop is proposed in this study.

The FPGA design process for centralized MPPT control is described in Fig. 3. The first step is "algorithm refinement." The next step is "modularity," which consists of "hierarchy" and "regularity." The final step is " $\mathrm{A}^{3}$ methodology," which is a configuration optimization. The controller is configured as a prototype for the proposed scheme, as shown in Fig. 4. Every PV system has an MPPT algorithm unit and PI controller. However, FPGA slice utilization increases in this case. The individual MPPT loop for every PV subsystem is a redundant structure because of the relatively slow sampling rate required for MPPT control. Multiple MPPT controllers increase the number of slices but reduce the number that can be implemented on an FPGA chip. The optimized proposed architecture customizes a single unified MPPT controller for all PV subsystems, with every PV subsystem having its own individual PI controller. The DFG for the unified MPPT algorithm unit is shown in Fig. 5. The centralized MPPT controller collects sensor data in each PV subsystem. For example, the sensed variables of " $n$ " $P V$ subsystems are $V_{p v 1}$, $I_{p v 1}, V_{p v 2}, I_{p v 2} \ldots V_{p v n}, I_{p v n}$. The sensed data are sampled sequentially according to the required MPPT algorithm period $\left(\mathrm{T}_{\mathrm{MPPT}}\right)$. The sampling frequency for the MPPT clock

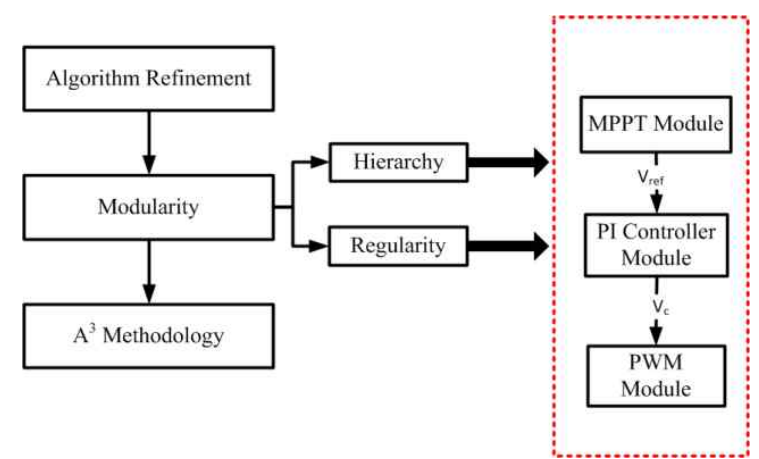

Fig. 3. FPGA Design Methodology for centralized MPPT controller.

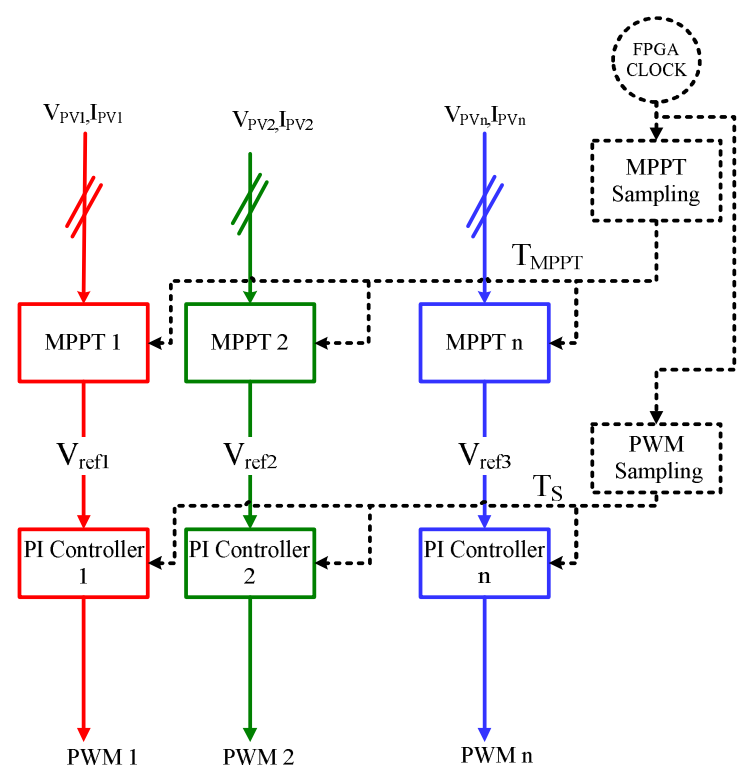

Fig. 4. Centralized controller with multiple MPPT algorithms for multiple PV modules.

is accordingly calculated from $\mathrm{f}_{\mathrm{MPPT}}\left(=\mathrm{n} / \mathrm{T}_{\mathrm{MPPT}}\right)$. The reference voltages $\left(\mathrm{V}_{\text {refl }}\right.$ to $\left.\mathrm{V}_{\text {refn }}\right)$ are sequentially processed in the specific PI control unit after calculation. Each reference voltage value is fixed during the specified MPPT period $\left(\mathrm{T}_{\mathrm{MPPT}}\right)$. The multiplexer and de-multiplexer shown in Fig. 5 enable MPPT module sequence selection in a single controller along with the instantaneous parallel operation of the PI controller [23].

The device utilization for two different architectures in Fig. 4 and Fig. 5 are compared in Table I. Data are based on central control unit implementation for three PV subsystems. The used FPGA is from the Xilinx Virtex II series and has 5120 slices. By implementing the architecture in Fig. 4, we observed that slice utilization is $47.6 \%$, excluding the PI parts. Slice utilization for a single MPPT architecture is $29.2 \%$ in Fig. 5. Implementing the three PI controllers resulted in a total slice utilization of $99 \%$ for the architecture in Fig. 4. The total slice utilization for the proposed architecture is only just $70 \%$. 


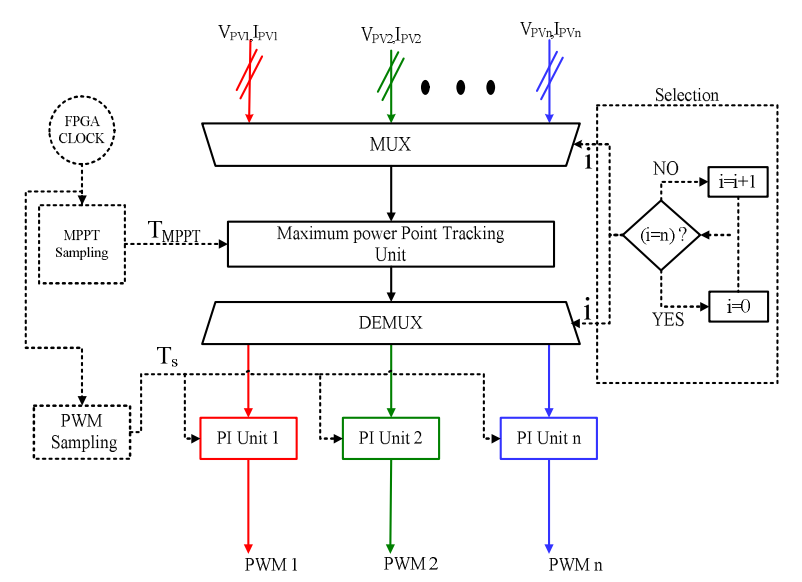

Fig. 5. Centralized controller with a unified MPPT algorithm for multiple PV modules.

TABLE I

FPGA UTILIZATION RATIOS FOR A CENTRALIZED CONTROLLER IN A PV POWER SYSTEM

\begin{tabular}{|c|c|c|c|c|c|}
\hline \multirow{2}{*}{ Items } & \multirow{2}{*}{$\begin{array}{c}\text { Total } \\
\text { number }\end{array}$} & \multicolumn{2}{|c|}{$\begin{array}{c}\text { Multiple MPPT } \\
\text { (Fig. 4) }\end{array}$} & \multicolumn{2}{c|}{$\begin{array}{c}\text { Single MPPT } \\
\text { (Fig. 5) }\end{array}$} \\
\cline { 3 - 6 } & & $\begin{array}{c}\text { Used } \\
\text { Slices }\end{array}$ & $\begin{array}{c}\text { Utilization } \\
\text { Percent }\end{array}$ & $\begin{array}{c}\text { Used } \\
\text { slices }\end{array}$ & $\begin{array}{c}\text { Utilization } \\
\text { Percent }\end{array}$ \\
\hline Slices & 5120 & 2438 & $47.6 \%$ & 1496 & $29.2 \%$ \\
\hline Registers & 10240 & 3064 & $29.9 \%$ & 1808 & $17.7 \%$ \\
\hline LUTs & 10240 & 2565 & $25.0 \%$ & 1724 & $16.8 \%$ \\
\hline RAMs & 40 & 0 & 0 & 0 & 0 \\
\hline
\end{tabular}

The newest single MPPT method allows the proposed architecture to integrate as much as seven PV systems, which is more than double the number of PV subsystems integrated in the other architecture. A design methodology for the PI feedback control loop is proposed in the next section, taking into account the nonlinear characteristics of PV sources.

\section{TRANSIENT ANALYSIS AND CONTROLLER DESIGN METHODOLOGY}

The PV generator is a nonlinear source of energy; the output characteristic of the PV generator is a function of solar radiation, temperature, and load conditions [24], [25]. The proposed MPPT controller is based on the P\&O method. A PI controller tracks the reference voltage, which is perturbed to observe output power change and to track the maximum power point of the $\mathrm{PV}$ generator. The $\mathrm{P}-\mathrm{V}$ curves for two different operating conditions of solar radiation are shown in Fig. 6. The PV generator tracks the maximum power point at $400 \mathrm{~W} / \mathrm{m}^{2}$ solar radiation (point "a" on the curve). A step change increases solar radiation to $1000 \mathrm{~W} / \mathrm{m}^{2}$ at this time. The new operating point becomes " $b$ " and the MPPT controller should drive the PV system to maximum power point "c." Therefore, the PI controller should track the reference under all three operating conditions. However, the

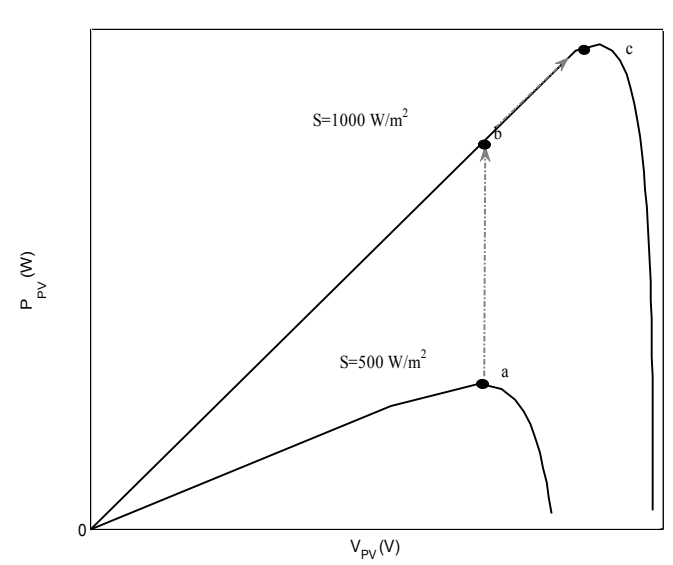

Fig. 6. Ideal MPPT controller trajectory during a step change (from $400 \mathrm{~W} / \mathrm{m}^{2}$ to $1000 \mathrm{~W} / \mathrm{m}^{2}$ ) in solar radiation.

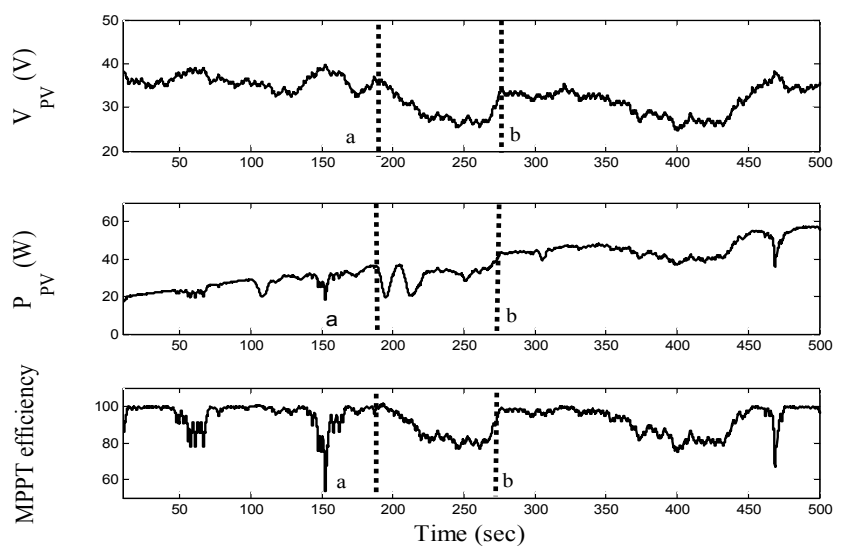

Fig. 7. Example of a failed PV controller (from a to b).

dynamic characteristics of the PV system are dependent to the ambient operating conditions and the operating point on the $\mathrm{P}-\mathrm{V}$ curve. Therefore, a PI controller designed for a single maximum power point does not guarantee successful reference tracking under other operating conditions. A case demonstrating this problem is shown by the experimental results shown in Fig. 7. The PI controller fails to track the reference at low solar radiation (between a and b). However, the PI controller was able to track the MPP at high radiation condition.

A PV generator model is derived with solar radiation and temperature as model input parameters. Subsequently, a transient analysis is applied to provide a generalized transfer function for the proposed PV system. According to the analysis, a Bode plot is sketched for different operating conditions to address the worst-case operating points.

The Shockley diode equivalent circuit model shown in Fig. 8 is used to model the PV module or array of modules. Current source $\mathrm{I}_{\text {light }}$ simulates the photo-generated current. $\mathrm{I}_{\text {diode }}$ represents the diode current of the solar cell PN junction. Shunt and series resistances represent the losses in the 


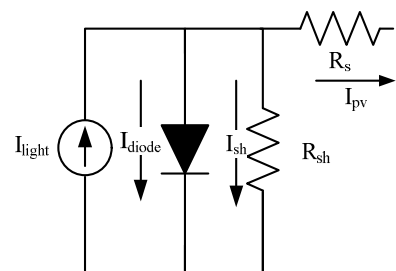

Fig. 8. PV generator model.

semiconductor body and across the wire connections, respectively [26]-[32]. Then, by Kirchhoff's current law,

$$
\mathrm{I}_{\mathrm{PV}}=\mathrm{I}_{\text {light }}-\mathrm{I}_{\text {diode }}-\mathrm{I}_{\mathrm{sh}} \text {. }
$$

From this equation, $\mathrm{I}_{\mathrm{PV}}$ can be calculated by using Equation (2). To simplify the analysis, the effect of shunt resistance $\left(R_{\text {sh }}\right)$ is neglected.

$$
I_{p v}=I_{\text {light }}-I_{0}\left(e^{\frac{V_{p v}+I_{p v} R_{s}}{A}}-1\right)-\frac{V_{p v}+I_{p v} R_{s}}{R_{s h}}
$$

Where,

$$
\mathrm{A}=\frac{\mathrm{mKT}_{\mathrm{c}}}{\mathrm{q}}
$$

The light generated current $\left(\mathrm{I}_{\text {light }}\right)$ near the short circuit current $\left(I_{s c}\right)$ is calculated from Equation (4). The subscript "ref" in all equations specifies the reference conditions of solar radiation and temperature, which are $1000 \mathrm{~W} / \mathrm{m}^{2}$ and $25{ }^{\circ} \mathrm{C}$, respectively.

$$
\mathrm{I}_{\text {light }} \cong \mathrm{I}_{s c} \cong \frac{\mathrm{S}}{\mathrm{S}_{\text {ref }}}\left(\mathrm{I}_{\text {sc_ref }}+\mu_{\text {sc }}\left(T_{c}-T_{c_{-} r e f}\right)\right)
$$

According to this model, a transient analysis is provided to derive a generalized transfer function for the PV system. The DC/DC converter used is a boost converter that integrates the PV source with the DC link. The equivalent circuit of the PV system is shown in Fig. 9. A voltage sink models the DC link, including DC link disturbance. Solar radiation (S), cell temperature $\left(\mathrm{T}_{\mathrm{c}}\right), \mathrm{DC}$ link voltage (e), and DC/DC boost converter duty ratio (d) are the equivalent circuit model inputs. The dynamic system model outputs are PV generator output voltage $V_{p v}$ and output current $i_{p v}$. The temperature dynamic is ignored for the small signal model. Assuming an ideal boost converter, Equations (5) and (6) are derived.

$$
\begin{aligned}
& v_{p v}=\frac{1}{C_{i n}}\left(i_{p v}-i_{L}\right) \\
& \dot{i_{L}}=\frac{1}{L}\left(v_{p v}-e(1-d)\right)
\end{aligned}
$$

After linearizing equations (5) and (6), each PV subsystem state space parameter can be represented by equations (7) and (8). Prefix $\delta$ denotes the small signal increments, whereas subscript 0 indicates steady-state values. Constants $\mathrm{Ks}$ and $\mathrm{K}_{\mathrm{PV}}$ are defined in equations (9) and (10). $\mathrm{R}_{\mathrm{PV}}$ is the instantaneous dynamic resistance defined in Equation (11).

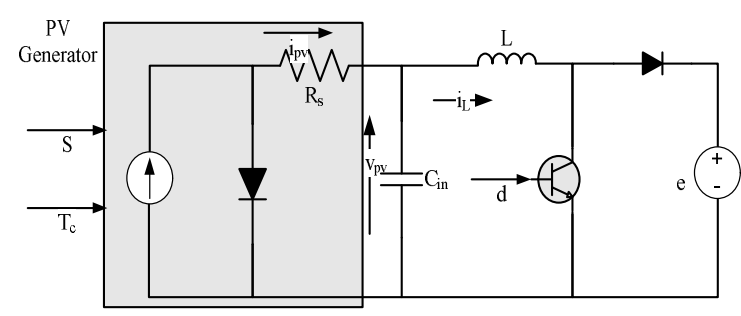

Fig. 9. Equivalent circuit model of PV power system.

$$
\begin{aligned}
& {\left[\begin{array}{c}
\delta \dot{i}_{L} \\
\delta \dot{v}_{p v}
\end{array}\right]=\left[\begin{array}{cc}
-\frac{R_{L}}{L} & \frac{1}{L} \\
-\frac{1}{C_{i n}} & \frac{K_{p v}}{C_{i n}}
\end{array}\right]\left[\begin{array}{c}
\delta i_{L} \\
\delta v_{p v}
\end{array}\right]+\left[\begin{array}{ccc}
\frac{E_{0}}{L} & 0 & -\frac{1-D_{0}}{L} \\
0 & \frac{K_{s}}{C_{i n}} & 0
\end{array}\right]\left[\begin{array}{l}
\delta d \\
\delta S \\
\delta e
\end{array}\right]} \\
& {\left[\begin{array}{l}
\delta i_{p v} \\
\delta v_{p v}
\end{array}\right]=\left[\begin{array}{cc}
0 & K_{p v} \\
0 & 1
\end{array}\right]\left[\begin{array}{c}
\delta i_{L} \\
\delta v_{p v}
\end{array}\right]+\left[\begin{array}{ccc}
0 & K_{s} & 0 \\
0 & 0 & 0
\end{array}\right]\left[\begin{array}{c}
\delta d \\
\delta S \\
\delta e
\end{array}\right]} \\
& K_{s}=\frac{\partial i_{p v}}{\partial S}=\frac{1}{S_{r e f}}\left(I_{s c_{-} r e f}+I_{\mathrm{sc}}\left(T_{c 0}-T_{c_{-} r e f}\right)\right) \\
& K_{p v}=\frac{\partial i_{p v}}{\partial v_{p v}}=\frac{-I_{0}}{A e^{\left(V_{p v 0}+R_{s} I_{p v 0}\right) / A}+I_{0} R_{s}} \\
& R_{p v}=\frac{1}{K_{P V}} .
\end{aligned}
$$

Finally, transfer function $\mathrm{GV}_{\mathrm{PV}}(\mathrm{s})$ from $\delta \mathrm{d}(\mathrm{s})$ to $\delta \mathrm{V}_{\mathrm{PV}}(\mathrm{s})$ can be derived from the state space representation. This transfer function is for a specific solar radiation and cell temperature condition. The temperature value affects $\mathrm{K}_{\mathrm{PV}}$ and transient characteristics. Solar radiation affects the transfer function dynamics and the steady-state values $\mathrm{V}_{\mathrm{PV} 0}$ and $\mathrm{I}_{\mathrm{PV} 0}$.

$$
G V_{P V}(s)=\frac{\delta V_{P V}(s)}{\delta d(s)}=\frac{-E_{0}}{L C_{i n} s^{2}-L / R_{P V} s+1}
$$

Equation (12) indicates that the transfer function is of the second order and is a function of dynamic transient resistance $R_{P V}$, which is a function of solar radiation, temperature, and load operating point. The I-V curves at two different solar radiation conditions are shown in Fig. 10. $R_{P V}$ versus $V_{P V}$ under the same conditions of the $I-V$ curve is shown in Fig. 10(b). The maximum $\mathrm{R}_{\mathrm{PV}}$ occurs during transient response (point " $b$ ") because $V_{P V}$ is the minimum and $i_{\mathrm{PV}}$ is the maximum among the three points. Bode plots for $\mathrm{GV}_{\mathrm{PV}}$ are sketched in Fig. 11 for different operating points in the I-V curve of Fig. 10. Bode plots show that point "b" has a peak Q-factor, implying an oscillatory system. The system becomes more damped as $\mathrm{V}_{\mathrm{PV}}$ increases to point "c." The system goes through all operating conditions under a typical PV system operation (see Figs. 6 and 7). 

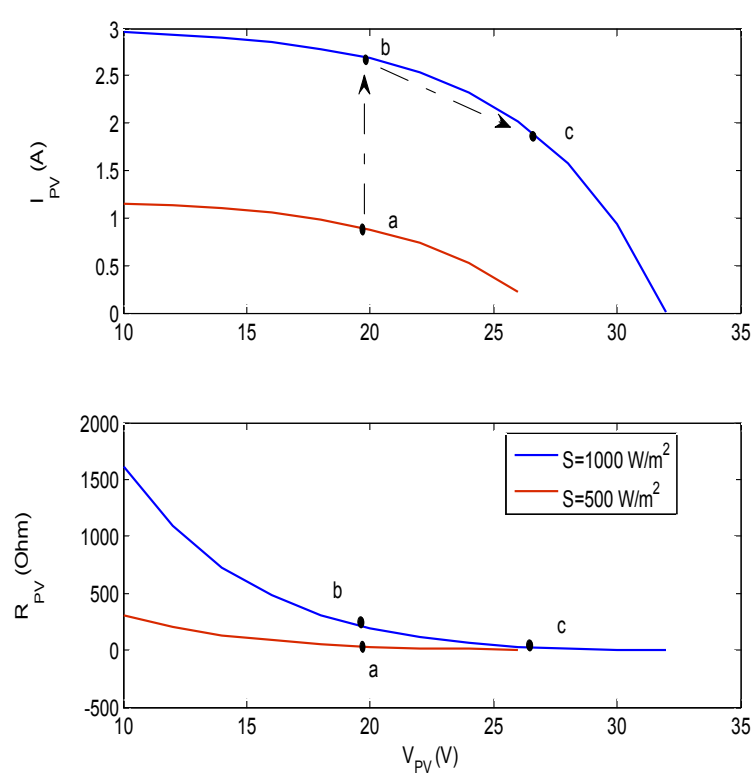

Fig. 10. V-I characteristics according to radiation change:(a) V-I characteristics and (b) $\mathrm{R}-\mathrm{V}$ characteristics.

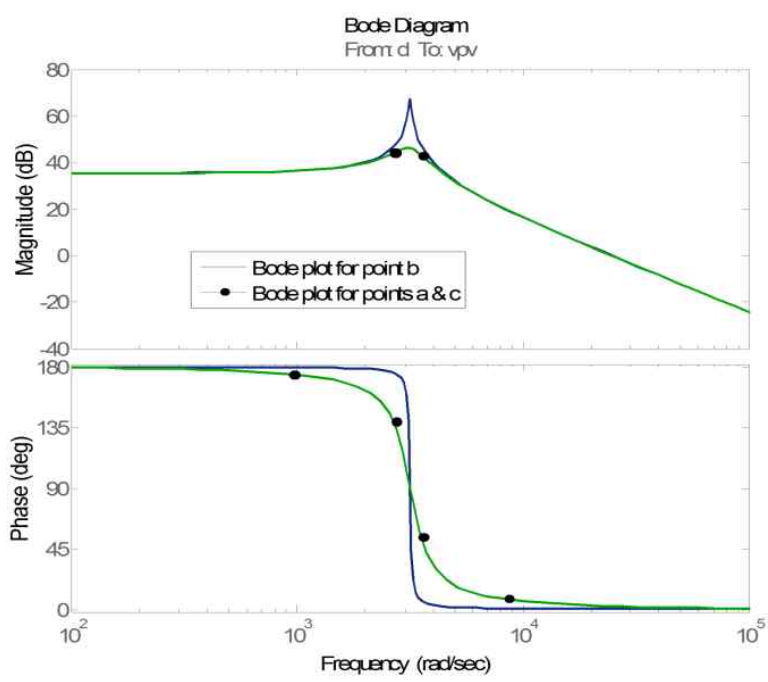

Fig. 11. Bode Plot for the PV system.

According to the analysis and discussion, the system should be designed for worst-case conditions to ensure stability and robust controller performance. The worst-case design point, including PV system transient trajectories, is the lowest operating voltage from the Bode plots in Fig. 11. This value should be carefully derived from the V-I curves under different solar radiation and temperature conditions.

\section{EXPERIMENTAL VERIFICATION}

The experimental test aims to verify the capability of the FPGA-based centralized controller to perform MPPT for multiple PV systems connected to a DC grid. A centralized control unit with seven PI control loops was developed; this

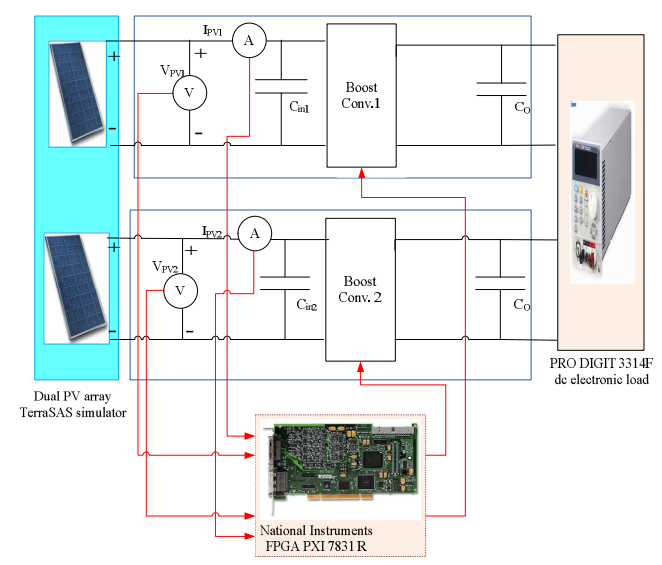

Fig. 12. Schematic diagram for the experimental setup.

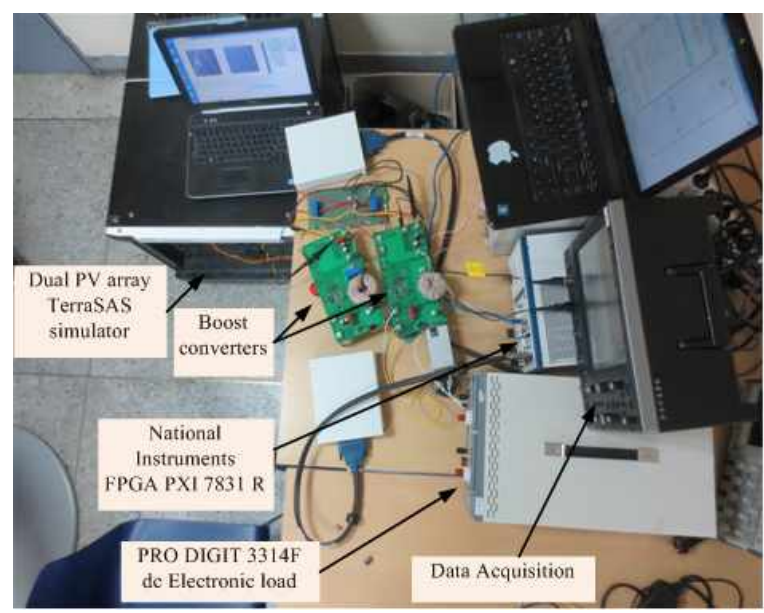

Fig. 13. Experiment test rig.

unit can control seven PV systems. The control unit was embedded in the National Instrument FPGA PXI 7831R unit, which contains a Xilinx Virtex II1000 FPGA chip. A dual PV TerraSAS simulator was used to emulate two different PV arrays. During the test, all seven loops were tied to each array and made to work continuously in two groups to demonstrate the parallel operation capability of the FPGA device. The switching frequency was $30 \mathrm{kHz}$, and the sampling time of the PI feedback control loop was $33 \mu \mathrm{s}$. If performance is to be realized by using DSP instead of FPGA, then a highperformance and expensive device is required to satisfy the speed requirement of multiple loop numbers.

A schematic diagram of the experimental setup is shown in Fig. 12. A test rig image is shown in Fig. 13. Each channel of the solar simulator emulates the individual solar array with a different $\mathrm{V}-\mathrm{I}$ curve, as shown in Fig. 14. Channels 1 and 2 are rated as $65 \mathrm{~W}$ and $80 \mathrm{~W}$, respectively. The different PV characteristics of the two channels show that both MPPT controllers work independently. The cloudy day profile shown in Fig. 15 emulates solar radiation and ambient temperature conditions for both simulator channels. 

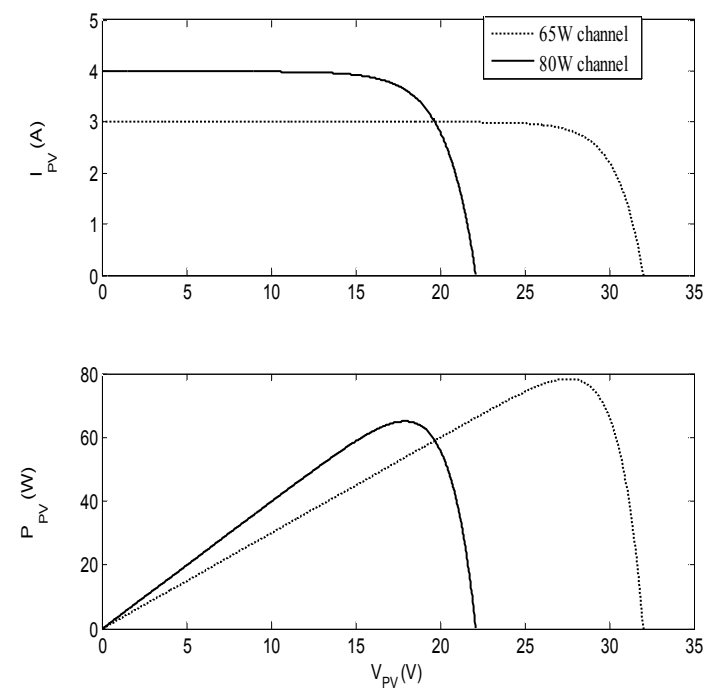

Fig. 14. V-I and P-V curves used in two channels $(60 \mathrm{~W}$ and 80 W) of the solar simulator.
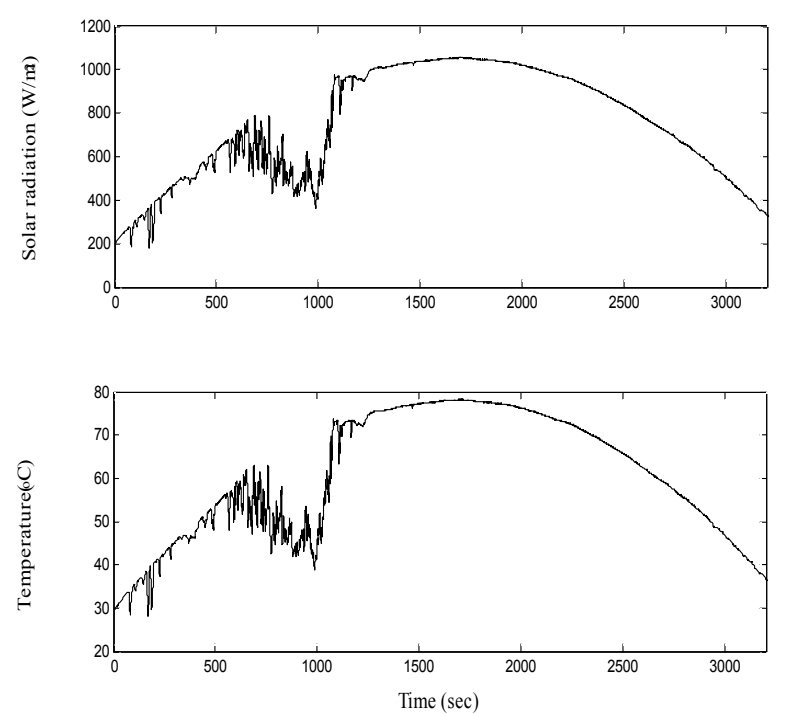

Fig. 15. Cloudy weather profile for a day: (a) solar radiation profile and (b) temperature profile [23].

The cloudy day profile was applied to both simulator channels for 150 min real time. A boost converter connected each simulator channel to the unified DC-link, which was emulated by a PRO DIGITAL 3314 DC electronic load (Fig. 13).

The central controller operation was verified by the test results presented in Fig. 16. The proposed central control unit swiftly and accurately tracks the maximum power points, even under fast-changing conditions of solar radiation and temperature for both channels. When the solar radiation and temperature profile of the solar array simulator was set to slowly changing environmental condition at the solar radiation of $400 \mathrm{~W} / \mathrm{m}^{2}$ at $700 \mathrm{~s}$, average MPPT efficiency of $99 \%$ was obtained. However, when the radiation and
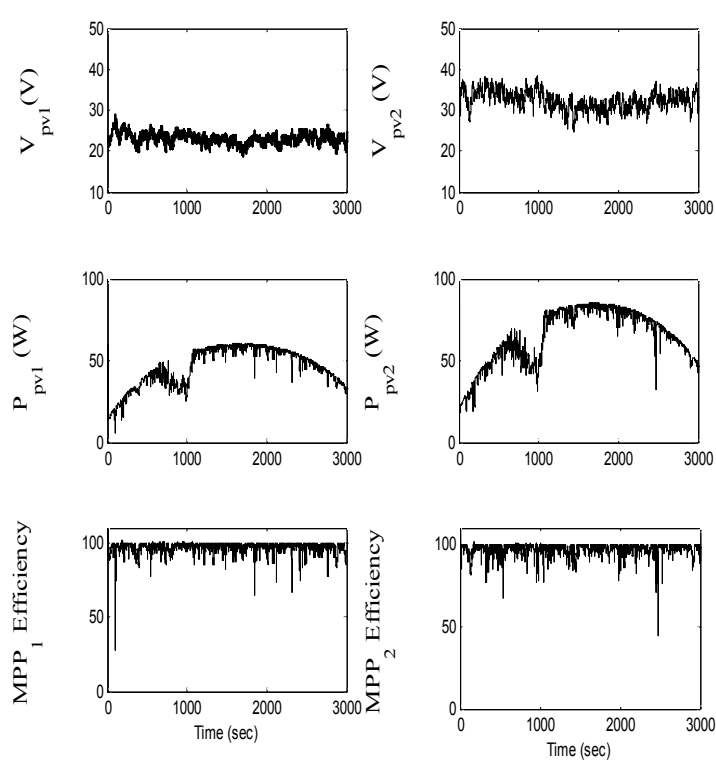

Fig. 16. MPP voltage, power, and efficiency curves.
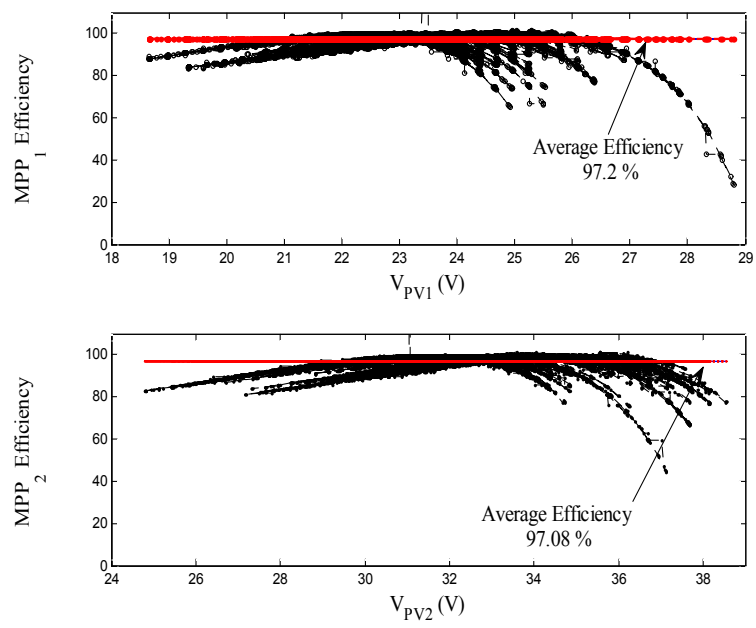

Fig. 17. MPPT efficiency vs. $V_{P V}$.

temperature profiles were rapidly changed at the solar radiation of $400 \mathrm{~W} / \mathrm{m}^{2}$ at $1000 \mathrm{~s}$, MPPT efficiency of $95 \%$ was measured. Both PV sources always exhibited different $\mathrm{V}_{\mathrm{PV}}$ and $\mathrm{P}_{\mathrm{PV}}$, which indicates that all control units operate independent of one another. MPPT efficiency versus $V_{P V}$ is shown in Fig. 17 using the data obtained from the experimental results for both channels in Fig. 16. The figure demonstrates an average efficiency (slightly more than 97\%) even under harsh operating conditions for both channels. The average efficiencies are calculated using MATLAB software.

The results demonstrate that many PI control loops with high sampling frequencies could be unified into a single FPGA chip without affecting control loop performance. Moreover, the unified MPPT controller works successfully even under cloudy weather conditions because of the robustness of the FPGA control design methodology. 


\section{CONCLUSIONS}

We presented a new FPGA-based central control unit for multiple PV systems connected to a DC grid. This study considered the parallelism of FPGA, which makes FPGAs different from DSPs. We proposed a detailed design process for implementing the centralized controller. This process includes the optimization of FPGA logic utilization. MPPT control for each PV system is the basic operation of the proposed centralized control unit, in which the PV system also requires an individual feedback-control inner loop.

We considered the worst-case V-I characteristic curve of the PV system in the proposed design methodology for the implementation of feedback-control loop. The PV system transfer function changes from a damping region to an oscillatory region when PV voltage changes under the transient response of the power conditioner.

Finally, we implemented and verified the central controller on the basis of experimental results. We used a dual channel simulator to simulate two PV systems. However, seven PI control loops were implemented on a single FPGA during the test. Each PI control loop is designed to operate at a sampling frequency of $30 \mathrm{kHz}$. The results show that the FPGA central controller can control the two PV groups in parallel. MPPT efficiencies obtained for both channels were slightly more than $97 \%$.

In future work, a battery bank will be included in the DC grid, whereas a battery charger controller will be included in the central control unit. Furthermore, a supervisory controller will be introduced to manage the different modes of system operation.

\section{ACKNOWLEDGEMENT}

This work was supported by Soongsil University Research Fund of 2011.

\section{REFERENCES}

[1] K. Kurohane, T. Senjyu, A. Yona, N. Urasaki, T. Goya and T. Funabashi, "A hybrid smart AC/DC power system," IEEE Trans. Smart Grid, Vol. 1, No. 2, pp. 199-204, Sep. 2010.

[2] U.S. Energy Information Administration. Annual report-IEA Photovoltaic Power Systems Programme's 2012, http://www.iea-pvps.org/index.php?id=6, Apr. 2013.

[3] S. Grillo, V. Musolino, L. Piegari, E. Tironi and C. Tornelli, "DC islands in AC smart grids," IEEE Trans. Power Electron., Vol. 29, No. 1, pp. 89-98, Jan. 2014.

[4] L. Xu and D. Chen, "Control and operation of a de microgrid with variable generation and energy storage," IEEE Trans. Power Del., Vol. 26, No. 4, pp. 2513-2522, Oct. 2011.

[5] F. Deng and Z. Chen, "Operation and control of a DC-grid offshore wind farm under DC transmission system faults," IEEE Trans. Power Del., Vol. 28, No. 3, pp. 1356-1363, Jul. 2013.

[6] M. García-Gracia, N. El Halabi, H. Ajami, and M. Comech, "Integrated control technique for compliance of solar photovoltaic installation grid codes," IEEE Trans. Energy Convers., Vol. 27, No. 3, pp. 792-798, Sep. 2012.

[7] B. Wang, M. Sechilariu, and F. Locment, "Intelligent DC microgrid with smart grid communications: control strategy consideration and design," IEEE Trans. Smart Grid, Vol. 3, No. 4, pp. 2148-2156, Dec. 2012.

[8] M. Martino, Y. F. Quinones, P. Raboni, and Z. Chen., "Intelligent control for a DC micro-grid system," in 47th International Universities Power Engineering Conference (UPEC), pp. 1-5, 2012.

[9] H. Valderrama-Blavi, J. M. Bosque, F. Guinjoan, M. Marroyo, and L. Martinez-Salamero, "Power adaptor device for domestic DC microgrids based on commercial MPPT inverters," IEEE Trans. Ind. Electron., Vol. 60, No. 3, pp. 1191-1203, Mar. 2013.

[10] E. Monmasson and M. N. Cirstea, "FPGA design methodology for industrial control systems - A review," IEEE Trans. Ind. Electron., Vol. 54, No. 4, pp. 1824-1842, Aug. 2007.

[11] P. Zumel, C. Fernández, M. Sanz, A. Lázaro, and A. Barrado, "Step-by-step design of an FPGA-based digital compensator for DC/DC converters oriented to an introductory course," IEEE Trans. Educ., Vol. 54, No. 4, pp. 599-609, Nov. 2011

[12] N. Khaehintung, T. Wiangtong, and P. Sirisuk, "FPGA implementation of MPPT using variable step-size P\&O algorithm for PV applications," IEEE international symposium on communication and information, pp. 212-215, 2006.

[13] Internet sites and online journals dedicated to FPGAs, such as: "FPGA-FAQ", http://www.fpga-faq.com/,"FPGA.

[14] S. Kjaer, "Evaluation of the "Hill Climbing" and the "Incremental Conductance" Maximum Power Point Trackers for Photovoltaic Power Systems," IEEE Trans. Energy Convers., Vol. 27, No. 4, pp. 922-929, Dec. 2012.

[15] Ahmed, L. Ran, M. Sol, and J. Park, "A fast PV power tracking control algorithm with reduced power mode," IEEE Trans. Energy Convers., Vol. 28, No. 3, pp. 565-575, Sep. 2013.

[16] T. Esram and P. Chapman, "Comparison of photovoltaic array maximum power point tracking techniques," IEEE Trans. Energy Convers., Vol. 22, No. 2, pp. 439-449, Jun. 2007.

[17] S. Padmanabhan, K. Kaliyappan, "High performance MPPT based on variable speed generator driven by wind power generation in battery applications," Journal of Electrical Engineering \& Technology, Vol. 9, No. 1, pp. 205213, Jan. 2014

[18] G-S. Kim, K.-B. Lee, D.-C. Lee, and J.-M. Kim, "Fault diagnosis and fault-tolerant control of DC-link voltage sensor for two-stage three-phase grid-connected PV inverters," Journal of Electrical Engineering \& Technology, Vol. 8, No. 4, pp. 752-759, Jul. 2013.

[19] J. Lee, J. Kim, Y.-H. Kim, Y.-H. Chun, S. H. Lee, J.-K. Seok, and Y. C. Kang, "Rotor speed-based droop of a wind generator in a wind power plant for the virtual inertial control," Journal of Electrical Engineering \& Technology, Vol. 8, No. 5, pp. 1021-1028, Sep. 2013.

[20] K. Abdelsalam, A. M. Massoud, S. Ahmed, and N. Prasad, "High-performance adaptive perturb and observe MPPT technique for photovoltaic-based microgrids," IEEE Trans. Power Electron., Vol. 26, No. 4, pp. 1010-1021, Apr. 2011.

[21] Subudhi and R. Pradhan, "A comparative study on maximum power point tracking techniques for photovoltaic 
power systems," IEEE Trans. Sustainable Energy, Vol. 4, No. 1, pp. 89-98, Jan. 2013.

[22] M. Miyatake, M. Veerachary, F. Toriumi, N. Fujii, and H. Ko, "Maximum power point tracking of multiple photovoltaic arrays: A PSO approach," IEEE Trans. Aerosp. Electron. Syst., Vol. 47, No. 1, pp. 367-380, Jan. 2011.

[23] P. Ganeshkumar, A. Ahmed, J.-H. Park, "FPGA based multi-module converter controller for photovoltaic maximum power point tracking," ICEMS, pp. 148-151, 2013.

[24] Y. Tian, B. Xia, Z. Xu, and W. Sun, "Modified asymmetrical variable step size incremental conductance maximum power point tracking method for photovoltaic systems," Journal of Power Electronics, Vol. 14, No. 1, pp. 156-164, Jan. 2014.

[25] M. Momayyezan and H. Iman-Eini, "Developed MPPT algorithm for photovoltaic systems without a voltage sensor," Journal of Power Electronics, Vol. 13, No. 6, pp. 1042-1050, Nov. 2013.

[26] E. V. Paraskevadaki and S. A. Papathanassiou, "Evaluation of MPP voltage and power of mc-Si PV modules in partial shading conditions," IEEE Trans. Energy Convers., Vol. 26, No. 3, pp. 923-932, Sep. 2011.

[27] F. Ghias and A. Behzad, "A new approach for solar module temperature estimation using the simple diode model," IEEE Trans. Energy Convers., Vol. 26, No. 4, pp. 1118-1126, Dec. 2011.

[28] J. A. Duffie and W. Beckman, Solar Engineering of Thermal Processes, $3^{\text {rd }}$ ed., Wiley, 2006.

[29] A. Chatterjee, A. Keyhani, and D. Kapoor, "Identification of photovoltaic source models," IEEE Trans. Energy Convers., Vol. 26, No. 3, pp. 883-889, Sep. 2011.

[30] M. E. Ropp and S. Gonzalez, "Development of a MATLAB/simulink model of a single-phase grid-connected photovoltaic system," IEEE Trans. Energy Convers., Vol. 24, No. 1, pp. 195-202, Mar. 2009.

[31] S. K. Ji, D. H. Jang, and S. S. Hong, "Analog control algorithm for maximum power trackers employed in photovoltaic applications," Journal of Power Electronics, Vol. 12, No. 3, pp. 503-508, May 2012.

[32] E. M. Ahmed and M. Shoyama, "Scaling factor design based variable step size incremental resistance maximum power point tracking for PV systems," Journal of Power Electronics, Vol. 12, No. 1, pp. 164-171, Jan. 2012.

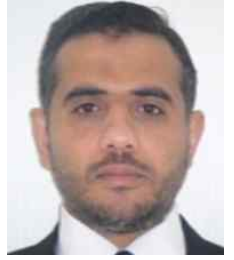

Ashraf Ahmed received his B.Sc. and M.Sc. degrees in Electrical Engineering from Assiut University-Egypt, Cairo UniversityEgypt in 1999 and 2005, respectively. He received his Ph.D. degree from University of Durham-UK in 2011, in the field of renewable energy control and power electronics. He is currently an Assistant Professor at Soongsil University, Seoul, Korea and a researcher in the Desert Research Center, Cairo, Egypt. His research interests include the analysis and design of switching power converters for renewable energy applications.

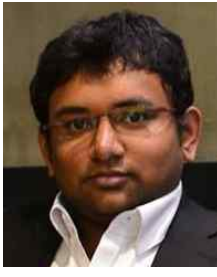

Pradeep Ganeshkumar received his B.S. degree from the Department of Electrical Engineering of Kalasalingam University, India, in 2011. He is currently pursuing his M.S. degree at Soongsil University. His current research interests include the analysis and design of FPGA-based power converters and renewable energy applications.

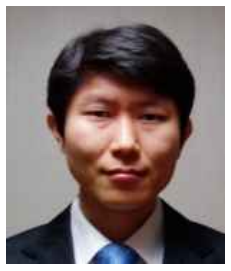

Joung-Hu Park received his B.S., M.S., and $\mathrm{Ph} . \mathrm{D}$. degrees from the Department of Electrical Engineering and Computer Science of Seoul National University, Seoul, Korea, in 1999, 2001 and 2006, respectively. $\mathrm{He}$ is currently an Assistant Professor at Soongsil University, Seoul, Korea. His current research interests include the analysis of high-frequency switching converters and renewable energy applications.

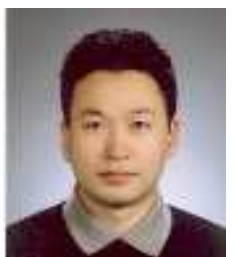

Hojin Lee received his Ph.D. degree in Electrical Engineering from the University of Michigan, Ann Arbor, USA, in 2008. He subsequently joined the Qualcomm MEMS Technologies, San Jose, CA, as a Senior Device Engineer working on MEMS devices for radio frequency and flat-panel display applications. From 1998 to 2003, he worked for BOE-HYDIS as a Senior Process Integration Engineer for TFT-LCD array processes. In 2010, he moved from Qualcomm to Soongsil University, Seoul, South Korea, as an Assistant Professor with the School of Electronic Engineering. His research interests include MEMS devices and electronics, TFTs and circuits, and flat-panel display technologies, including OLED and sensors. 